\title{
Psychiatric Symptoms of Epileptic Nature: An Old Hypothesis in Light of Current Psychopharmacologic Advances
}

\author{
Javier Alvarez-Rodriguez \\ Departamento de Psiquiatría, Complejo Asistencial Universitario de León, León, Spain \\ Email: jar1950@hotmail.com
}

Received 3 January 2015; accepted 26 January 2015; published 30 January 2015

Copyright (C) 2015 by author and Scientific Research Publishing Inc.

This work is licensed under the Creative Commons Attribution International License (CC BY). http://creativecommons.org/licenses/by/4.0/

(c) $\underset{\mathrm{EY}}{\mathrm{B}}$ Open Access

\begin{abstract}
This paper analyses a hypothesis according to which many positive psychiatric symptoms should be interpreted as symptoms of epileptic nature. When we first raised this proposition, almost fifteen years ago, it was inconsistent with the widespread conviction among psychiatrists that psychopharmacological drugs used to suppress psychiatric symptoms were proconvulsant. But lately, there have appeared numerous neuroscientific investigations that defend the anticonvulsant effect of most psychopharmacological drugs, hence supporting our hypothesis. We have carried out bibliographical reviews in search of the pro- or anticonvulsant role of these substances, particularly lithium, selective serotonin reuptake inhibitors, dual antidepressants, and antipsychotic drugs. These researches show abundant evidence regarding the anticonvulsant action of these substances, a fact that contributes to a better comprehension of paradoxical relationship between epilepsy and psychoses.
\end{abstract}

\section{Keywords}

Antipsychotic Drugs, Dual Antidepressants, Lithium, Mental Automatisms, SSRIs

\section{Introduction}

Basing us in still valid writings of renowned neuro-psychiatrists of the past century [1] [2], we postulated nearly fifteen years ago an innovative psychiatric hypothesis in which we proposed the epileptic nature of many psychiatric symptoms [3] [4]. In these previous writings, we said that productive and/or positive psychic manifestations should be interpreted as expression of simple partial seizures (SPSs) when they appeared in the next way: suddenly the attention focused completely on the sole psychic event occurring in mind at this moment. This phenomenon is always experienced with the same phenomenological features: distortion of inner time, automat- 
ic character, great intensity, and strong feeling of strangeness. We have been investigating the epileptic origin of these experiences along these years, and recently we proposed to term them Hipersyncronic Mental Automatisms (HMAs) [5].

The best way to understand these phenomena is by means of an example of a HMA which occurs so frequently among the normal population that many of us will surely have experienced it. We are referring to déjà vu, "a paroxysmal feeling of familiarity which can be found in no less than half the normal population, but which just as easily can be conceived as a partial seizure” ([6], p. 103). Well, this paramnesia contains the five features which we have described just above as defining a HMA: sudden focusing of attention, distorted inner time, completely passively received (automatic), very intense, and charged with an incomprehensible strangeness.

Psychiatric practice recognizes a great variety of psychic phenomena with these clinical characteristics, and in light of their frequency and content, the following list of HMAs may be drawn up:

1) Perceptive automatisms: These are hallucinatory phenomena that impose themselves on the consciousness with undeniable conviction of truth.

2) Cognitive automatisms:

a) Primary delusional ideas [7], where a sudden though that entails always the impression of irrefutable certainty.

b) Depersonalization: the subject suddenly has the vivid impression of observing himself as wholly or partially different from normal, despite knowing that the sense organs are working properly.

c) Derealization: this is similar to depersonalization, but now it is the environment, not the self; that is suddenly changed.

3) Affective automatisms:

a) Panic attack, that is, an acute assault of anguish and terror taking over the consciousness with such sudden intensity that the subject has the impression that he is losing the control of his mind.

b) Sadness attack: here the unexpected experience consists of a sudden psychic pain invading the awareness completely and for no apparent reason, the sorrow being inexplicable for the subject suffering it.

c) Joy attack: the opposite of the above. It is a state of intense bliss with no apparent cause, which takes over consciousness passively.

d) Alternative acute attacks of these two opposite affective experiences that mimic a quick cycling bipolar disorder.

So far, these psychic productions have constituted a grey area between psychiatry and neurology, sometimes being diagnosed as SPSs when there is a concordant EEG and more frequently as symptoms of different psychiatric disorders. Indeed, hallucinations and primary delusional ideas are two of the characteristic symptoms of acute psychoses, more specifically of an acute state of paranoid schizophrenia and/or schizophrenia-like psychosis, and are commonly diagnosed as such. In turn, depersonalization and derealization are the characteristic symptoms of depersonalization disorder. Panic attacks are regularly diagnosed as panic disorder. Painful experiences are often interpreted as symptoms of a melancholic depression, while the opposite joyful experiences are included in the manic phase of bipolar disorder. Finally, automatically alternating experiences of joy and suffering are usually diagnosed as rapid cycling bipolar disorder.

Now, when we proposed for the first time that these psychic manifestations were SPSs [3], such interpretation was in direct conflict with the conviction widely held in psychiatry that psychotropic drugs used to treat them had a proconvulsant action. Indeed, the most handbooks of psychiatry in force at that time warmed that psychopharmacological drugs favored neuronal convulsiveness and therefore could not be administered to epileptic patients, or could only be employed with great care [8]. This was especially true for lithium [9], for tricyclic antidepressants [10], but also was applied to SSRIs [11].

Consequently, it was very difficult to find at that time psychopharmacological bibliography by means of which sustained our hypothesis. But along recent years, there have appeared numerous scientific papers defending the anticonvulsant effect of most of these substances and, hence, supporting our proposition. Thus, we will do the consequent scientific researches about this topic.

\section{Methodology}

The five main families of psychotropic drugs used to suppress AMHs are benzodiazepines, mood stabilizers, 
SSRIs, dual antidepressants (DAs), and antipsychotics (APs). The anticonvulsant role of benzodiazepines is recognized by all neuroscientific community, so there is not problem with this group of drugs. Similarly, the anticonvulsant effect of mood stabilizers is unquestioned since they all, except lithium, are anticonvulsant drugs by definition. So, the problem arises with lithium, SSRIs, tricyclic antidepressants (TaDs), modern DAs, and APs that are the supposedly proconvulsant substances.

In an attempt to throw light on this question, we have looked for information on the action actually played by these substances on neuronal transmission. The database employed was PubMed, using advance search, for following terms: anticonvulsant, antiepileptic drugs (AEPs), APs, atypical APs, citalopram, clomipramine, modern DAs, fluoxetine, imipramine, lithium, neuroleptics, proconvulsant, serotonin, sertraline, SSRIs and TCAs.

\section{Results}

Before to detail the specific findings of our researches for every one of drugs above listed, we consider necessary to establish some general considerations about the results:

1) Firstly, the information used for many year ago to justify their proconvulsant role came from studies of doubtful scientific value [12], mainly for two reasons: many times the proconvulsant action was inferred from investigations carried out with animal models, in which the doses employed was much higher that these ones used in psychiatric clinical practice [13]; on the other hand, the studies in humans did not take in account the strong inherited propensity to epilepsy of people included in such investigations [14].

2) Secondly, the results are not only conclusive but even confuse with some authors defending interchangeably the anticonvulsant and proconvulsant action of these drugs.

One these clarifications made, we will group all information found supporting our hypothesis into the following sections: 1) anticonvulsant effect of lithium; 2) anticonvulsant effect of SSRIs; 3) anticonvulsant effect of DAs; 4) anticonvulsant effect of APs.

\subsection{Anticonvulsant Effect of Lithium}

Lithium is the first substance introduced in psychopharmacology as a mood stabilizer, that is, to prevent depressive and/or manic relapses of bipolar disorder, with over sixty years of use [15]. Its mechanism of action has remained unknown for a long time but in the last three decades there have appeared evidences supporting the anticonvulsant effect of this drug [16]-[18].

Different mechanisms have been postulated to explain this effect of lithium. So, a modification in glutamate neurotransmission could be the cause of this anticonvulsant action [16] [17]. Concretely, Pérez-Siles et al. [19] conclude that lithium inhibits glycine transporters with the subsequent decrease of glutamate neurotransmission. See comment in PubMed Commons below. Other authors think that this anticonvulsant effect would be operated by means of a modification of different gene expressions, such as a reduction of glutamate receptor subunit genetic expression [20] or modifying Wnt dependent gene expression [21]. Finally, numerous authors opine that lithium operates its anticonvulsant action reinforcing gabergictransmission, for example with lithium replacing sodium at GABA transporter GAT-1 [22] [23].

\subsection{Anticonvulsant Effect of SSRIs}

Similarly, the reviews carried out on SSRIs did not only highlight the questionable proconvulsant role traditionally attributed to SSRIs but also revealed credible information about their anticonvulsant effect. Indeed, we found many studies supporting the idea that the serotonergic reinforcement of these drugs has an anticonvulsant action, a fact remarkably observed with fluoxetine [24]-[30].

\subsection{Anticonvulsant Effect of DAs}

DAs reuptake serotonin and norepinephrine, while SSRIs only reuptake serotonin. We can distinguish two main groups of DAs: classic tricyclic antidepressants (TcAs), with clomipramine and amitriptyline as the most widely used, and modern DAs, with venlafaxine and duloxetine as the most used.

When we posed for the first time the potential anticonvulsant role of TcAs [3], it looked little realistic because these substances had a recognized ability to reduce seizure threshold and to provoke epileptic seizures, two facts unanimously shared by psychiatrists and neurologists at that time [10]. 
But after carrying out our researches looking for their potential anticonvulsant action we found evidences similar to those on SSRIs. There had been investigations defending this anticonvulsant effect for years in which the authors hypothesized different mechanisms to explain the anticonvulsant role of TcAs [31]-[33]. Curiously Jobe and Browning [34] published an article whose title alone, "The serotoninergic and noradrenergic effects of antidepressant drugs are anticonvulsant, not proconvulsant", summarizes all our argumentations on this topic. More recently other authors [35] [36] have recently highlighted the anticonvulsant role of second-generation antidepressants.

\subsection{Anticonvulsant Role of APs}

Regarding APs we could say something similar to what we have previously state about lithium, SSRIs, and DAs. APs are drugs that have been used in psychiatry since the middle of last century for the treatment of psychotic syndromes, being particularly effective for the positive symptoms, such as hallucinations and delusions, two of the events that we have included within the HMAs, and therefore interpreted as SPSs.

Classic APs or neuroleptics are substances that act as antagonists of dopamine, and their antipsychotic effect is due to the D2 receptors blockage; the extrapyramidal symptoms of these drugs would depend on the D1 receptor blockade. The main characteristic of new antipsychotic drugs, or atypical anyipsychotics, is that they do not act, or act just weakly, on D1 receptors, helping to avoid extrapyramidal symptoms. They also act as antagonists on 5-HT2 receptors, resulting in a reinforcement of the serotonergic transmission, an action that seems to play a contributing role in suppressing psychotic symptoms.

APs have also traditionally been considered substances that lower seizure threshold, with frequent occurrence of epileptic fits in patients in treatment with these drugs. But, as we previously said regarding other families of psychopharmacological drugs, our bibliographical reviews on this topic showed realistic information that supported that this supposedly proconvulsant role of APs lacked scientific and methodological rigor [37] [38]. On the other hand, we found well documented scientific researches postulating the anticonvulsant action of these substances. Clozapine, olanzapine and risperidone seem to enhance GABA neurotransmission a fact that would explain their anxiolytic action similar to benzodiazepines and which is independent of their specific antipsychotic effect [39]-[42].

Glutamate hypothesis of schizophrenia has also been used to explain the hypothetic anticonvulsant action of APs. According to this, many manifestations of schizophrenia would be due to an alteration on the glutamatergic transmission, and specifically to an imbalance between NMDA and non-NMDA neurotransmitters [43]-[46].

Finally, it is necessary to add that recent studies suggest that antidepressants and APs, on the one hand, and antiepileptic drugs, on the other hand, share synergistic pharmacokinetic mechanisms that lead to a reciprocal enhancement of the therapeutic effect of both families of drugs [38] [47] [48].

\section{Discussion}

When it comes to evaluating these results, it is necessary to emphasize a striking fact that we have found in many of the investigations consulted: numerous pieces of information are confusing and even contradictory, with authors defending both the proconvulsant and anticonvulsant role of certain psychotropic drugs at the same time, for example depending on the doses. We think that this confuse and opposite information could be explained to a large extent if we take into account the probable existence of two different and antagonistic kinds of epileptic activities [49]-[51]. Wilson and Bragdon [52] allude to these opposite epileptic activities in the next terms:

These data suggest a possible new principle for the relationship between epileptic form bursts and electrographic seizures, namely, that they can arise in separate, mutually interactive, locations. Moreover, although epileptic bursts can trigger electrographic seizures, their main effect may be to suppress seizures arising in their target areas. Thus, interictal spikes in humans may have a suppressive effect on seizure discharge (p. 380).

Probably this opposite effect of epileptic burst and electrographic seizures is mediated by simultaneous activation of postsynaptic AMPA and NMDA receptors, which elicit complex and even opposing responses [53].

The existence of two opposing opposed epileptiogenic activities helps us to understand the contradictions above mentioned. Furthermore, split of epileptic activity in two different types offer us a natural explanation 
clarification of the contradictory relationship between epilepsy and psychoses, a paradox that Starr [54] summarizes in the next terms:

One of the great unresolved medical controversies of the twentieth century concerns the relationship between epilepsy and psychosis. Limbic structures are suspected of being intimately involved in the pathophysiology of both of these neurological conditions, yet more than a century medical thinkers have failed to agree upon whether these two common disorders are closely associated, unrelated, or mutually antagonistic to one another (p. 160).

Indeed, on one hand, it is an undeniable fact the high comorbidity of epilepsy and psychoses. On the other hand, these two activities are incompatible simultaneously, as we can easily deduce from the next three facts:

1) The phenomenon termed "forced normalization" [55].

2) The often clinical observation that a generalized seizure terminates a state of acute psychosis [56].

3) The still effective treatment of psychoses with electro-convulsive therapy after eighty year of use [57].

This enigmatic information on the relationship of epilepsy and psychoses is naturally explained by our hypothesis. Indeed epilepsy is to hyperia what firefighter's water is to fire of a conflagration: both them frequently appear together but they antagonistic and even incompatible at the same time.

Finally, our proposal about the anticonvulsant effect of psychopharmacological drugs would make it possible to offer a comprehensible explanation to why AEDs are proving useful in an ever-growing number of psychiatric applications: for several decades they have been used as mood regulators to prevent relapses of bipolar disorder, while more and more scientific studies postulate their value to treat different psychiatric disorders such as anxiety [58], positive syndrome of schizophrenia and schizophrenic-like psychoses [59], but remarkably bipolar disorder [60], which not only responds to AEDs but even seems to share etiologic and pathogenic mechanisms with epilepsy [61].

\section{Conclusion}

There are abundant evidences suggesting that most psychopharmacological drugs can act as anticonvulsant, a fact that contributes to a better comprehension of paradoxical relationship between epilepsy and psychoses. It is necessary to carry out further studies to elucidate the role of each and every one of these substances on neuronal transmission.

\section{Declaration of Conflicting Interests}

The author declared no potential conflicts of interest with respect to the research, authorship, and/or publication of this article.

\section{Funding}

The author declared no potential conflicts of interest with respect to the research, authorship, and/or publication of this article.

\section{References}

[1] Wilson, S.A. (1928) Modern Problems in Neurology. Edward Arnold, London.

[2] Ey, H. (1954) Études Psychiatriques. Desclée de Brower, Paris.

[3] Álvarez, J. (2001) Neuronal Hypersyncronization, Creativity and Endogenous Psychoses. Medical Hypotheses, 56, 672-685. http://dx.doi.org/10.1054/mehy.2000.1269

[4] Alvarez-Rodriguez, J., Alvarez-Silva, S. and Alvarez-Silva, I. (2005) Epilepsy and Psychiatry: Automatic Psychic Paroxysms. Medical Hypotheses, 65, 671-675. http://dx.doi.org/10.1016/j.mehy.2005.03.030

[5] Alvarez-Rodriguez, J. (2014) Psychic Neuronal Hypersynchronies: A New Psychiatric Paradigm? Health (Irvine, California), 6, 2089-2099.

[6] Devinsky, O. and Luciano, D. (1991) Psychic Phenomena in Partial Seizures. Seminars in Neurology, 11, 100-109. http://dx.doi.org/10.1055/s-2008-1041211

[7] Jaspers, K. (1997) General Psychopathology. The Johns Hopkins University Press, Baltimore.

[8] Mendez, M. (2000) Comprehensive Textbook of Psychiatry. In: Sadock, B. and Sadock, V., Eds., Neuropsychiatric 
Aspects of Epilepsy, Lippincott Williams \& Wilkins, Philadelphia, 261-273.

[9] Clifford, D.B., Olney, J.W., Maniotis, A., Collins, R.C. and Zozumski, C.F. (1987) The Functional Anatomy and Pathology of Lithium-Pilocarpine and High-Dose Pilocarpine Seizures. Neuroscience, 23, 953-968. http://dx.doi.org/10.1016/0306-4522(87)90171-0

[10] Pisani, F., Oteri, G., Costa, C., Di Raimondo, G. and Di Perri, R. (2002) Effects of Psychotropic Drugs on Seizure Threshold. Drug Safety, 25, 91-110. http://dx.doi.org/10.2165/00002018-200225020-00004

[11] Rosenstein, D.L., Nelson, J.C. and Jacobs, S.C. (1993) Seizures Associated with Antidepressants: A Review. Journal of Clinical Psychiatry, 54, 289-299.

[12] Krishnamoorthy, E.S. (2003) Treatment of Depression in Patients with Epilepsy: Problems, Pitfalls, and Some Solutions. Epilepsy \& Behavior, 4, S46-S54. http://dx.doi.org/10.1016/j.yebeh.2003.08.017

[13] Dailey, J.W. and Naritoku, D.K. (1996) Antidepressants and Seizures: Clinical Anecdotes Overshadow Neuroscience. Biochemical Pharmacology, 52, 1323-1329. http://dx.doi.org/10.1016/S0006-2952(96)00509-6

[14] Barry, J.J. (2003) The Recognition and Management of Mood Disorders as a Comorbidity of Epilepsy. Epilepsia, 44, 30-40. http://dx.doi.org/10.1046/j.1528-1157.44.s4.4.x

[15] Cole, N. and Parker, G. (2012) Cade’s Identification of Lithium for Manic-Depressive Illness-The Prospector Who Found a Gold Nugget. Journal of Nervous \& Mental Disease, 200, 1101-1104. http://dx.doi.org/10.1097/NMD.0b013e318275d3cb

[16] Ghasemi, M. and Dehpour, A.R. (2011) The NMDA Receptor/Nitric Oxide Pathway: A Target for the Therapeutic and Toxic Effects of Lithium. Trends in Pharmacological Sciences, 32, 420-434. http://dx.doi.org/10.1016/j.tips.2011.03.006

[17] Li, B., Zhang, S., Li, M., Zhang, H., Hertz, L. and Peng, L. (2009) Down-Regulation of GluK2 Kainate Receptor Expression by Chronic Treatment with Mood-Stabilizing Anti-Convulsants or Lithium in Cultured Astrocytes and Brain, but Not in Neurons. Neuropharmacology, 57, 375-385. http://dx.doi.org/10.1016/j.neuropharm.2009.07.004

[18] Young, W. (2009) Review of Lithium Effects on Brain and Blood. Cell Transplantation, 18, 951-975. http://dx.doi.org/10.3727/096368909X471251

[19] Pérez-Siles, G., Morreale, A., Leo-Macías, A., Pita, G., Ortíz, AR. and Aragon, C. (2011) Molecular Basis of the Differential Interaction with Lithium of Glycine Transpoerters GLYT1 and GLTY2. Journal of Neurochemistry, 118, 195204. http://dx.doi.org/10.1111/j.1471-4159.2011.07309.x

[20] Valdes, J.J. (2009) Estrogen and Lithium: Facilitating Factors Involved in Brain Cell Signaling Pathways. FIU Electronic Theses and Dissertations, Paper 105. http://digitalcommons.fiu.edu/etd/105

[21] Phiel, C.J., Zhang, F., Huang, E.Y., Guenther, M.G., Lazar, M.A. and Kein, P.S. (2001) Histone Deacetylase Is a Direct Target of Valproic acid, a Potent Anticonvulsant, Mood Stabilizer, and Teratogen. The Journal of Biological Chemistry, 276, 36734-36741. http://dx.doi.org/10.1074/jbc.M101287200

[22] Andrini, O., Meinild, A.K., Ghezzi, C., Murer, H. and Forster, I.C. (2011) Lithium Interactions with Na ${ }^{+}$-Coupled Inorganic Phosphate Cotransporters: Insights into the Mechanism of Sequential Cation Binding. American Journal of Physiology-Cell Physiology, 302, C539-C554.

[23] Zhou, Y., Zomot, E. and Kanner, B.I. (2006) Identification of a Lithium Interaction Site in the Gamma-Aminobutyric Acid (GABA) Transporter GAT-1. The Journal of Biological Chemistry, 281, 22092-22099. http://dx.doi.org/10.1074/jbc.M602319200

[24] Hong, L. and Bainbridge, J.L. (2014) Anticonvulsant Effects of SSRIs. Mental Health Clinician, 2, 19.

[25] Buchanan, G.F., Murray, N.M., Hajek, M.A. and Richerson, G.B. (2014) Serotonin Neurones Have Anti-Convulsant Effects and Reduce Seizure-Induced Mortality. The Journal of Physiology, 592, 4395-4410. http://dx.doi.org/10.1113/jphysiol.2014.277574

[26] Faingold, C.L. and Randall, M. (2013) Effects of Age, Sex, and Sertraline Administration on Seizure-Induced Respiratory Arrest in the DBA/1 Mouse Model of Sudden Unexpected Death in Epilepsy (SUDEP). Epilepsy \& Behavior, 28, 78-82.

[27] Vermoesen, K., Massie, A., Smolders, I. and Clinckers, R. (2012) The Antidepressants Citalopram and Reboxetine Reduce Seizure Frequency in Rats with Chronic Epilepsy. Epilepsia, 53, 870-878. http://dx.doi.org/10.1111/j.1528-1167.2012.03436.x

[28] Mostert, J.P., Koch, M.W., Heerings, M., Heersman, D.J. and De Heyser, J. (2008) Therapeutic Potential of Fluoxetine in Neurological Disorders. CNS Neuroscience \& Therapeutics, 14, 152-164.

[29] Magyar, J., Rusnák, Z., Harasztosi, C., Körtvélv, A., Pacher, P. and Bánvász, T. (2003) Differential Effects of Fluoxetine Enantiomers in Mammalian Neural and Cardiac Tissues. International Journal of Molecular Medicine, 11, 535542. 
[30] Favale, E., Audenino, D., Cocito, L. and Albano, C. (2003) The Anticonvulsant Effect of Citalopram as an Indirect Evidence of Serotonergic Impairment in Human Epileptogenesis. Seizure, 12, 316-318. http://dx.doi.org/10.1016/S1059-1311(02)00315-1

[31] Jabourian, A.P., Erlich, M., Desvignes, C., el Hadjam, M. and Bitton, R. (1992) Panic Attacks and 24-Hour Ambulatory EEG Monitoring. Annales Médico-Psychologiques, 150, 240-244.

[32] Sakakihara, Y., Oka, A., Kubota, M. and Ohash, Y. (1995) Reduction of Seizure Frequency with Clomipramine in Patients with Complex Partial Seizures. Brain \& Development, 17, 291-293. http://dx.doi.org/10.1016/0387-7604(95)00040-I

[33] Yang, Y.-C. and Kuo, C.-C. (2002) Inhibition of $\mathrm{Na}^{+}$Current by Imipramine and Related Compounds: Different Binding Kinetics as an Inactivation Stabilizer and as an Open Channel Blocker. Molecular Pharmacology, 62, 1228-1237. http://dx.doi.org/10.1124/mol.62.5.1228

[34] Jobe, P.C. and Browing, R.A. (2005) The Serotonergic and Noradrenergic Effects of Antidepressant Drugs Are Anticonvulsant, Not Proconvulsant. Epilepsy \& Behavior, 7, 602-619. http://dx.doi.org/10.1016/j.yebeh.2005.07.014

[35] Alper, K., Schwaetz, K.A., Kilts, R.L. and Khan. A. (2007) Seizure Incidence in Psychopharmacological Clinical Trials: An Analysis of Food and Drug Administration (FDA) Summary Basis of Approval Reports. Biological Psychiatry, 62, 345-354. http://dx.doi.org/10.1016/j.biopsych.2006.09.023

[36] Borowicz, K.K., Golyaska, D., Luszczki, J.J. and Czuczwar, S.J. (2011) Effect of Acutely and Cronichally Administered Venlafaxine on the Anticonvulsant Action of Classical Antiepileptic Drugs in the Mouse Maximal Electroshock Model. European Journal of Pharmacology, 670, 114-120. http://dx.doi.org/10.1016/j.ejphar.2011.08.042

[37] Hedges, D., Jeppson, K. and Whitehead, P. (2003) Antipsychotic Medication and Seizures: A Review. Drugs of Today, 39, 551-557. http://dx.doi.org/10.1358/dot.2003.39.7.799445

[38] de Leon, J. (2014) False-Negative Studies May Systematically Contaminate the Literature on the Effects of Inducers in Neuropsychopharmacology. Part I: Focus on Epilepsy. Journal of Clinical Psychopharmacology, 34, 177-183. http://dx.doi.org/10.1097/JCP.0000000000000093

[39] Marx, C.E., VanDroren, M.J., Duncan, G.E., Lieberman, J.A. and Morrow, A.L. (2003) Olanzapine and Clozapine Increase the GABAergic Neuroactive Steroid Allopregnanolone in Rodents. Neuropsychopharmacology, 28, 1-13. http://dx.doi.org/10.1038/sj.npp.1300015

[40] Mead, A., Li, M. and Kapur, S. (2008) Clozapine and Olanzapine Exhibit an Intrinsic Anxiolytic Property in Two Conditioned Fear Paradigms: Contrast with Haloperidol and Chlordiazepoxide. Pharmacology Biochemistry and Behavior, 90, 551-562.

[41] Sun, T., He, W., Hu, G. and Li, M. (2010) Anxiolitic-Like Property of Risperidone and Olanzapine as Examined in Multiple Measures of Fear Rats. Pharmacology Biochemistry and Behavior, 95, 298-307. http://dx.doi.org/10.1016/j.pbb.2010.02.005

[42] Rogóz, Z. and Skuza, G. (2011) Anxiolitic-Effects of Olanzapine, Risperidone and Fluoxetine in Elevated Plus-Maze Test in Rats. Pharmacological Reports, 63, 547-552. http://dx.doi.org/10.1016/S1734-1140(11)70719-8

[43] Kantrowitz, J. and Javvit, DC. (2012) Glutamatergic Transmission in Schizophrenia: From Basic Research to Clinical Practice. Current Opinion in Psychiatry, 52, 96-102.

[44] Moghaddam, B. and Javvit, D. (2012) From Revolution to Evolution: The Glutamatergic Hypothesis of Schizophrenia and Its Implication for Treatment. Neuropsychopharmacology, 37, 4-15. http://dx.doi.org/10.1038/npp.2011.181

[45] Sendt, K.V., Giarolly, G. and Tracy, D.K. (2012) Beyond Dopamine: Glutamate as a Target for Future Antipsychotics. ISRN Pharmacology, 2012, Article ID: 427267. http://dx.doi.org/10.5402/2012/427267

[46] Paz, R.D., Tardito, S., Atzori, M. and Tseng, K.Y. (2008) Glutamatergic Dysfunction in Schizophrenia: From Basic Neuroscience to Clinical Psychopharcology. European Neuropsychopharmacology, 18, 773-786. http://dx.doi.org/10.1016/j.euroneuro.2008.06.005

[47] Diaz, F., Eap, C.B., Ansermot, N., Cretoll, S., Spina, E. and de Leon, J. (2014) Can Valproic Acid Be an Inducer of Clozapine Metabolism? Pharmacopsychiatry, 47, 89-96. http://dx.doi.org/10.1055/s-0034-1371866

[48] Italiano, D., Spina, E. and de Leon, J. (2014) Pharmacokinetic and Pharmacodinamic Interactions between Antiepileptic and Antidepressant. Expert Opinion on Drug Metabolism \& Toxicology, 10, 1457-1489. http://dx.doi.org/10.1517/17425255.2014.956081

[49] Cepeda, C., André, V.M., Jocoy, E.L. and Levine, M.S. (2009) NMDA and Dopamine: Diverse Mechanisms Applied to Interacting Receptors Systems. In: Van Dongen, A.M., Ed., Biology of the NMDA Receptor, Taylor and Francis Group, Boca Raton, 41-57.

[50] Uva, L., Librizzi, L., Wendling, F. and Curtis, M. (2005) Propagation Dynamics of Epileptiform Activity Acutely Induced by Bicuculline in the Hippocampal-Parahippocampal Region of the Isolated Guinea Pig Brain. Epilepsia, 46, 
1914-1925. http://dx.doi.org/10.1111/j.1528-1167.2005.00342.x

[51] Gale, K. (1993) Focal Trigger and Pathways of Propagation in Seizure Generation. In: Schwartzkroin, P.A., Ed., Epilepsy: Models, Mechanisms and Concepts, Cambridge University Press, Cambridge, 48-93. http://dx.doi.org/10.1017/CBO9780511663314.004

[52] Wilson, W.A. and Bragdon, A. (1993) Brain Slice Models for The Study of Seizures and Interictal Spikes. In: Schwartzkroin, P.A., Ed., Epilepsy: Models, Mechanisms and Concepts, Cambridge University Press, Cambridge, 371387.

[53] Traynelis, S.F., Wollmuth, L.P., McBrain, C.J., Meniti, F.S., Vance, K.M. and Ogden, K.K. (2010) Glutamate Receptor Ions Channels: Structure, Regulation, and Function. Pharmacological Reviews, 62, 405-496. http://dx.doi.org/10.1124/pr.109.002451

[54] Starr, M.S. (1996) The Role of Dopamine in Epilepsy. Synapse, 22, 159-194. http://dx.doi.org/10.1002/(SICI)1098-2396(199602)22:2<159::AID-SYN8>3.0.CO;2-C

[55] Wolf, P. (1991) Acute Behavioral Symptomatology at Disappearance of Epileptiform EEG Abnormality. Paradoxical or "Forced" Normalization. Advances in Neurology, 55, 127-142.

[56] Pollock, D.C. (1987) Models for Understanding the Antagonism between Seizures and Psychosis. Progress in NeuroPsychopharmacology Biological Psychiatry, 11, 483-504. http://dx.doi.org/10.1016/0278-5846(87)90017-0

[57] Finn, M. (1986) Convulsive Therapy and Epilepsy Research. In: Trimble, M.R. and Reynolds, E.H., Eds., What Is Epilepsy? Churchill Livingstone, Edinburgh, 217-228.

[58] Van Ameringen, M., Manzini, C., Pipe, B. and Benett. M. (2004) Antiepileptic Drugs in Treatment of Anxiety Disorders: Role in Therapy. Drugs, 64, 2199-2220. http://dx.doi.org/10.2165/00003495-200464190-00004

[59] Landmark, C.J. and Johannessen, S.I. (2010) New Antiepileptic Drugs in Neuropsychiatric Disorders. In: Ritchner, M.S., Ed., Brain Protection in Schizophrenia, Mood and Cognitive Disorders, Springer, New York, 485-504.

[60] Cookson, J. and Elliot, B. (2006) The Use of Anticonvulsants in the Aftermath of Mania. Journal of Psychopharmacology, 20, 23-30. http://dx.doi.org/10.1177/1359786806063073

[61] Mazza, M., Di Nicola, M., Della Marca, G., Janiri, L., Bria, P. and Mazza. S. (2007) Bipolar Disorder and Epilepsy: A Biridectional Relation? Neurobiological Underpinings, Current Hypotheses, and Future Research Directions. Neurocientist, 13, 392-404. http://dx.doi.org/10.1177/10738584070130041101 
Scientific Research Publishing (SCIRP) is one of the largest Open Access journal publishers. It is currently publishing more than 200 open access, online, peer-reviewed journals covering a wide range of academic disciplines. SCIRP serves the worldwide academic communities and contributes to the progress and application of science with its publication.

Other selected journals from SCIRP are listed as below. Submit your manuscript to us via either submit@scirp.org or Online Submission Portal.
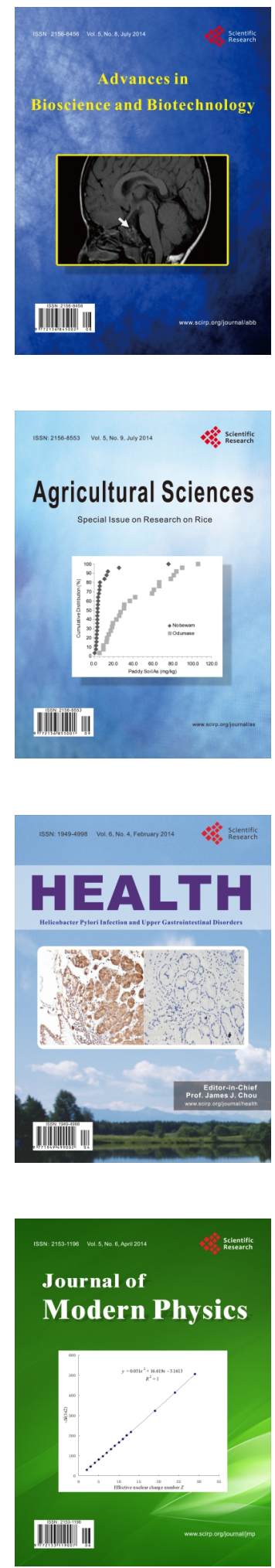
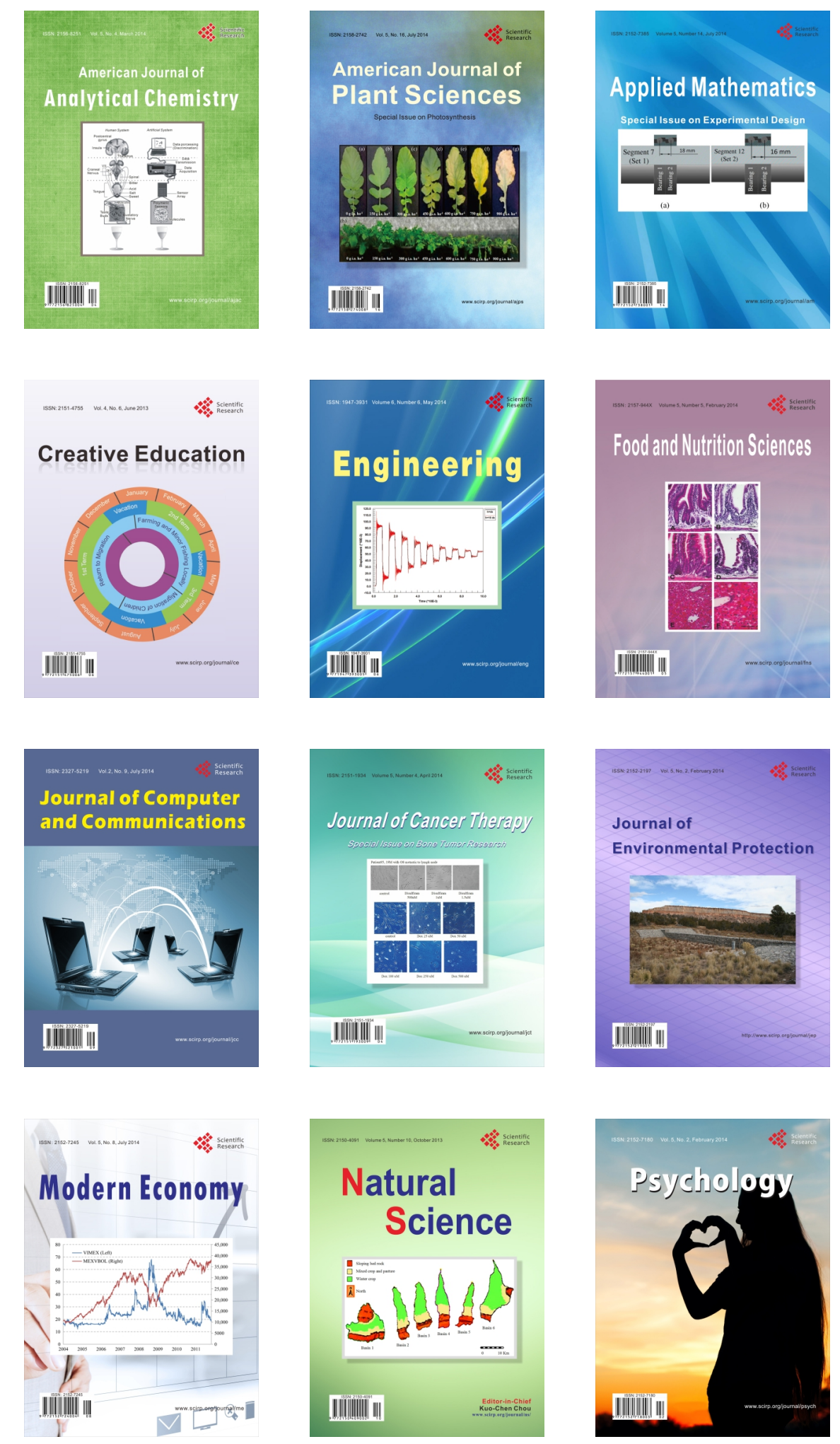